\title{
Cumulative Plastic Deformation Characteristics of Saturated Silty Sand under Variable Frequency Cyclic Loading of Subway Entrance/Exit
}

\section{Zeyao Li}

Tongji University

Jie Zhou ( $\square$ zhoujie1001@tongji.edu.cn )

Tongji University

\section{Wanjun Tian}

China Construction Second Engineering Division

\section{Yiqun Tang}

Tongji University

\section{Wansheng Pei}

Northwest Institute of Eco-Environment and Resources State Key Laboratory of Frozen Soil Engineering

\section{Research Article}

Keywords: variable frequency cyclic loading, subway entrance/exit acceleration, cumulative deformation, undrained dynamic triaxial test

Posted Date: March 15th, 2021

DOl: https://doi.org/10.21203/rs.3.rs-177521/v1

License: (1) This work is licensed under a Creative Commons Attribution 4.0 International License.

Read Full License 


\title{
Cumulative Plastic Deformation Characteristics of Saturated Silty Sand under Variable Frequency Cyclic Loading of Subway Entrance/Exit
}

\author{
Zeyao $\mathrm{Li}^{1}$, Jie Zhou ${ }^{1}$, Wanjun Tian $^{2}$, Yiqun Tang ${ }^{1}$, Wansheng Pei ${ }^{3}$ \\ 1. Department of Geotechnical Engineering, Tongji University, Shanghai, China, 200092 \\ 2. China Construction Second Engineering Bureau Co., Ltd., Beijing, 100074 \\ 3. State Key Laboratory of Frozen Soil Engineering, Northwest Institute of Eco-Environment and Resources, CAS, Lanzhou, China, 730000
}

Zeyao Li. Graduate Student, Department of Geotechnical Engineering, Tongji University.

Department of Geotechnical Engineering, Tongji University, Shanghai 200092, People's Republic of China;

Phone: 8618721912732

Fax: 86021-65987079

Email: lzy004@tongji.edu.cn

Jie Zhou. Associate Professor (corresponding author), Department of Geotechnical Engineering, Tongji University. Department of Geotechnical Engineering, Tongji University, Shanghai 200092, People's Republic of China; Phone: 8613636651710

Fax: 86021-65987079

E-mail:zhoujie1001@tongji.edu.cn 
Abstract The acceleration and deceleration movement of the subway near the subway station have a certain impact on the foundation soil. After the samples have been reconstituted in an inclined slope using sand rain method, undrained dynamic cyclic triaxial experiments were designed under specific variable frequency loading condition according to on-site monitoring data and theoretical calculation results. Effects of subway entrance/exit distance, subway entrance/exit acceleration, vibration amplitude, effective confining pressure on the cumulative deformation characteristics of Nanjing saturated silty sand were explored under experimental program. The results show that the cumulative plastic strain development of the Nanjing silty sand under the variable frequency cyclic loading of subway entrance/ exit can be roughly divided into three stages: explosive growth, rapid growth and gradual stability. The increase of the distance from the subway station can reduce the vibration cycles of subway entrance/exit loading to enter the gradual stabilization phase;

11 it can also lower the shear deformation and increase the vertical deformation. Greater the vibration amplitude or lower the effective confining pressure can also have the same effect on soil deformation characteristics.

13 Instead, greater the subway entrance/ exit acceleration, smaller the vertical deformation and larger the shear

14 deformation. For practical engineering, the initial stage of subway line in operation is the focus of engineering

15 geological disaster prevention. The settlement deformation of the soil in subway entrance interval, the

16 horizontal displacement of the soil in subway exit interval are more serious. The soil closer to subway station

17 is more prone to deformation hazard

18 Keywords: variable frequency cyclic loading, subway entrance/exit acceleration, cumulative deformation,

19 undrained dynamic triaxial test

\section{$20 \quad$ List of symbols}

\footnotetext{
$\sigma_{\mathrm{d}} \quad$ vertical stress caused by subway entrance/exit (kPa)

$\tau_{d}$ horizontal shear stress caused by subway entrance/exit ( $\left.\mathrm{kPa}\right)$

$a_{s}$ subway entrance/exit acceleration $\left(\mathrm{m} / \mathrm{s}^{2}\right)$

$\mathrm{g}$ the acceleration of gravity $\left(\mathrm{m} / \mathrm{s}^{2}\right)$

$\sigma_{1}$ maximum principal stress controlled by dynamic triaxial test $(\mathrm{kPa})$

$\sigma_{3}$ minimum principal stress controlled by dynamic triaxial test $(\mathrm{kPa})$

$\theta$ sample preparation angle $\left(^{\circ}\right)$

$\varepsilon_{\mathrm{d}}$ vertical stress under the loading of subway entrance/exit

$\varepsilon_{1}$ axial strain of the samples under dynamic triaxial test

$\gamma$ shear strain of the samples under the loading of subway entrance/exit

$v$ the dynamic Poisson's ratio

$\varepsilon_{\mathrm{p}}$ cumulative plastic strain

$N$ the number of cyclic vibration

$a$ the test parameter related to cumulative deformation rate
} 
$b$ the test parameter related to the deformation of the soil after the first cyclic loading

$c$ the test parameter related to the final deformation of the soil

\section{Introduction}

Different from the condition of running with constant speed, the subway entrance/exit acceleration or deceleration can not only cause a certain number of variable frequency cyclic loading, but also can generate horizontal shear stress.

Researches on the vibration of the subway train with variable speed includes: Huang and Thambiratnam (2001) studied the deflection response of plate on Winkler foundation to moving accelerated loads. Michaltsos (2002) theoretically analyzed the linear dynamic response of a simply supported elastic singlespan beam subjected to a moving load of constant magnitude and variable velocity. Kim and Mccullough (2003) studied the dynamic response of plate on viscous Winkler foundation to moving loads of varying amplitude. Degrande et al. (2006) presented the results of in situ vibration measurements that have been performed within the frame of the CONVURT project at a site in Regent's Park on the Bakerloo line of London Underground during 35 passages of a test train at a speed between 20 and $50 \mathrm{~km} / \mathrm{h}$. Lu et al. (2010) investigated the vibrations of a plate on viscoelastic foundation under moving rectangular loads with variable speeds, and derived the general solution of dynamic deflection of the plate using the double Fourier transform; Zhang (2011) studied the dynamic response of the vehicle-structure dynamic coupling system when the trains of Shenzhen Metro Line 4 and Line 6 brake at Shenzhen North Station, and analyzed and evaluated the vibration state of the key parts of the station structure. Karimi and Ziaei-Rad (2015) conducted the study concerning with nonlinear coupled vibration analysis of a beam with moving supports under the action of a moving mass. Zhang and Chen $(2016,2017)$ analyzed the cylindrical longitudinal vibration and vibration source characteristics caused by the subway entering the station, and obtained the change law of the train's vibration response in the direction of the station. He (2018) numerically simulated the track vibration of moving subway under different acceleration and deceleration. Chen and Zhang (2019) used analytical methods to analyze the difference in soil vibration and spatial vibration characteristics caused by subway entering and leaving the station. For the vibrations of subway moving with variable speed, most of the studies are focus on the dynamic response of the track or foundation using analytical or numerical simulation methods. There are few studies on the cumulative strain of the foundation soil near the subway station. 
The area near the subway station is the focus of subway engineering prevention. Researches on the cumulative plastic deformation characteristics of the foundation soil near the subway station can help subway track and foundation deformation control and ensure the safety of subway operation. The unidirectional vibrations caused by dynamic cyclic triaxial could not effectively simulate the horizontal shear stress caused by subway entrance/exit acceleration. After the sample has been reconstituted in an inclined slope using sand rain method, undrained dynamic cyclic triaxial test is conducted to explore the effects of subway entrance/exit distance, subway entrance/exit acceleration, vibration amplitude, effective confining pressure on the cumulative deformation characteristics of Nanjing saturated silty sand.

\section{Loading condition}

Subway operation along Yangtze River Delta is aimed in this paper. The speed curve in operation of Nanjing Metro Line 3\# in China is shown in Fig.1:

Fig.1 Speed curve of Nanjing Metro in operation (a) time; (b) distance

The running state of a subway in a station mainly includes 7 stages of "constant acceleration-idlevariable torque traction-small level braking-idle-braking-stop". In the Yangtze River Delta region of China, the subway exit acceleration is about $0.83-1.03 \mathrm{~m} / \mathrm{s}^{2}$, and the entrance deceleration is about $0.50-0.60 \mathrm{~m} / \mathrm{s}^{2}$. Fig.2. When a subway entrance or exit, it can not only cause a certain amount of variable frequency vertical cyclic loading due to its own 12 sets of wheels squeezing the sleepers, but also apply horizontal shear stress to the soil due to the acceleration. The regular variable frequency cyclic loading generated by a cycle of subway entrance/exit can be defined as a vibration cycle of subway entrance/exit.

Fig.2 The subway carriages size of Nanjing Metro

\section{Experimental Program}

69

\section{Materials}

Silty sand layer near the Shangyuanmen subway station of Nanjing Metro Line 3\# along the Yangtze river is mainly focused. It belongs to a river typical floodplain facies soil layer, with water environment deposition (Hu et al. 2016). In this area, groundwater level is high. it is saturated. The main component of Nanjing silty sand is quartz debris. It is flaky structure and anisotropic (Chen et al. 2003). The particle characteristic of Nanjing silty sand is shown in Fig.3, and the basic physical parameters are shown in Tab.1: 
Fig.3 Particle characteristic of Nanjing silty sand (a) grain size; (b) particle shape

Tab.1 Basic physical parameters of saturated Nanjing silty sand

\section{Test plan}

Most of the dynamic triaxial test studies (Ren, et al. 2011; Tang et al. 2018) made the soil samples vibrate under the loading in vertical direction. This type of soil loading cannot effectively simulate the horizontal shear stress generated by the acceleration of subway entry/exit. If the silty sand sample is inclined to reconstitution, the stress state of the soil under the subway entrance/exit loading which includes the compressive stress in the vertical direction and shear stress in the horizontal direction can be equivalent simulated by controlling the principal stress of the samples. The test simulates and studies the cumulative plastic deformation characteristics of silty sand under the subway entrance/exit loading by inclined sand rain method of sample preparation and the undrained dynamic cyclic triaxial test system. Vertical stress $\sigma_{\mathrm{d}}$ and horizontal shear stress $\tau_{\mathrm{d}}$ caused by subway entrance/exit should meet:

$$
\frac{\tau_{d}}{\sigma_{d}}=\frac{a_{\mathrm{s}}}{g}
$$

Where: $a_{\mathrm{s}}$ is subway entrance/exit acceleration $\left(\mathrm{m} / \mathrm{s}^{2}\right)$; $\mathrm{g}$ is the acceleration of gravity $\left(\mathrm{m} / \mathrm{s}^{2}\right)$.

Axial pressure $\sigma_{1}$, confining pressure $\sigma_{3}$ controlled by dynamic triaxial test, and sample preparation in a inclined angle $\theta$ should meet:

$$
\begin{gathered}
\sigma_{1}=\frac{\sigma_{\mathrm{d}}}{2}+\sqrt{\left(\frac{\sigma_{\mathrm{d}}}{2}\right)^{2}+\tau_{\mathrm{d}}{ }^{2}} \\
\sigma_{3}=\frac{\sigma_{d}}{2}-\sqrt{\left(\frac{\sigma_{d}}{2}\right)^{2}+\tau_{d}^{2}} \\
\theta=\frac{1}{2} \arctan \left(-\frac{2 \tau_{d}}{\sigma_{d}}\right)
\end{gathered}
$$

Fig.4 Soil stress state under the loading of subway entrance/exit

Nanjing silty sand is a kind of remarkable flaky structural sand under water environment sedimentary. In order to ensure the structure of the sample particle arrangement, the sand rain method is used for sample reconstitution. After drying and sieving, the silty sands were reconstituted by underwater sand rain method under control of compactness parameters. The sample preparation device for controlling inclined angle is shown as Fig.5. The water level is $1 \mathrm{~m}$ higher than the sand accumulation device (Chen et al. 2003). The compactness of sand samples can be initially controlled by falling distance and falling amount of sand rain 
101 method. Then it can be accurately controlled by soil sample compactor. The length and diameter of sand 102 samples are $80.0 \mathrm{~mm}$ and $38.0 \mathrm{~mm}$. After reconstituted samples were completely prepared, they were stored 103 in a vacuum saturator for 24 hours to keep saturation.

104 Fig.5 Sample preparation device of underwater rain method

105 In Nanjing area, the buried depth of the subway tunnel is about $10 \mathrm{~m} \sim 15 \mathrm{~m}$, the groundwater level is 106 about $0.4 \mathrm{~m} \sim 1.1 \mathrm{~m}$, the vertical vibration basic value of subway loading is about $30 \mathrm{kPa}$, and vertical vibration 107 amplitude is about $10 \mathrm{kPa} \sim 20 \mathrm{kPa}$ (Tang and $\mathrm{Li} 2018$ ). Since subway entrance/exit acceleration is much 108 smaller than the acceleration of gravity, it makes the axial pressure increment caused by subway vibration is 109 much larger than the confining pressure increment caused by subway vibration $\left(\Delta \sigma_{3}<1 \% \Delta \sigma_{1}\right)$. Thus, this

110 experimental program ignores the confining pressure increment caused by subway vibration $\Delta \sigma_{3}$. The test

111 is carried out by means of unidirectional vibration isostatic consolidation. This paper sets $250 \mathrm{kPa}$ confining

112 pressure, $125 \mathrm{kPa}$ back pressure, $30 \mathrm{kPa}$ vertical vibration basic value, and $15 \mathrm{kPa}$ vertical vibration amplitude

113 as the basic test group for comparison according to the field stress condition. The whole experimental

114 program is designed as Tab.2 to explore the effects of subway entrance/exit distance, subway entrance/exit

115 acceleration, vibration amplitude, effective confining pressure on the cumulative deformation characteristics

116 of the silty sand.

117 Tab.2 Experimental program

118 The motion state of the subway when entrance/exit can directly affect the loading. According to on-site 119 monitoring data (Tang et al. 2018) and theoretical calculation results (Chen and Zhang 2019), variable 120 frequencies combined sinusoidal wave can effectively simulate the subway entrance/exit vibration mode.

121 Taking B4-B6 as examples, the dynamic triaxial axial stress time history curve is shown in Fig.6.

122 Fig.6 Dynamic triaxial axial compression stress time history curve (a) B4; (b) B5; (c) B6

\section{Test process}

124 First, control the deposition angle and make triaxial silty sand samples with height of 80mm, diameter 125 of $38 \mathrm{~mm}$. Second, saturate the sample in a vacuum saturator for 24 hours, and then install it in the triaxial 126 pressure chamber of GDS system and use the back pressure function for saturation. When the B value reaches 127 0.98, the saturation is regarded as completion (Zhou and Tang 2018). Finally after an isostatically 
consolidation for 24 hours, the axial dynamic loading is applied for testing. The test ends when the sample undergoes 5000 times variable cycles of subway entrance/exit or the axial strain reaches $15 \%$.

\section{Test results}

\section{The effects of subway entrance/exit distance on the cumulative plastic deformation}

Different the subway entrance/exit distance, different speed the subway runs. This makes the silty sand is subjected by different vibration loading when subway runs, and resultantly further affects its deformation characteristics. Through the dynamic triaxial test results, the axial strain and shear strain of soil induced by the loading of subway entrance/ exit can be restored:

$$
\begin{gathered}
\varepsilon_{\mathrm{d}}=\frac{\varepsilon_{1}-v \varepsilon_{1}}{2}+\frac{\varepsilon_{1}+v \varepsilon_{1}}{2} \cos 2 \theta \\
\gamma=\left(\varepsilon_{1}+v \varepsilon_{1}\right) \sin 2 \theta
\end{gathered}
$$

Where: $\varepsilon_{\mathrm{d}}$ is the axial strain of the sample under the loading of subway entrance/exit; $\varepsilon_{1}$ is the axial strain of the sample under dynamic triaxial test; $\gamma$ is the shear strain of the sample under the loading of subway entrance/exit; $v$ is the dynamic Poisson's ratio which can be obtained from the wave velocity test on the engineering site.

Fig.7 Soil strain state under the loading of subway entrance/exit

Fig. 8 shows the relationship between the vertical cumulative plastic strain of the silty sand with different subway entrance/exit distances and vibration cycles of subway entrance/exit loading; Fig.9 shows the relationship between the cumulative plastic shear strain of silty sand with different subway entrance/exit distances and vibration cycles of subway entrance/exit loading; Fig.8 and Fig.9 show that: under the loading of subway entrance, the maximum vertical cumulative deformation of the silty sand is about $0.7 \% \sim 1.1 \%$, and the maximum cumulative shear deformation is about $0.11 \% \sim 0.15 \%$. Under the loading of subway exit, the maximum vertical cumulative deformation is about $1.5 \%$ 2.0\%, and the maximum cumulative shear deformation is about $0.17 \% \sim 0.24 \%$;

For different subway entrance/exit distances, the characteristics of cumulative plastic strain curves of the silty sand are roughly the same. The strain curve can be roughly divided into three stages of development: in the initial stage, the strain increased exponentially, resulting in more cumulation of plastic strain in a short time; in the middle stage, the growth rate of plastic strain decreases with vibration cycle times of subway entrance/exit. When the vibration cycle number of subway entrance/exit reaches $600-1200$, the soil strain 
enters the stable stage. In addition, the closer to the subway station, the fewer vibration cycles of subway entrance/exit loading that the soil can enter the stage of gradual stability. The soil strain in subway entrance interval can earlier enter the gradual stabilization stage, especially the shear strain. It shows that the strain of soil in subway entrance/exit interval, whether vertical strain or shear strain, have the largest growth rate in the initial stage of subway line in operation. The initial stage of subway line in operation is the focus of engineering geological disaster prevention. With the continuous application of vibration loading, the soil

162 gradually tends to be dense and the strain rate decreases.

163 Fig.8 Cumulative vertical plastic strain time history curve

164 Fig.9 Cumulative plastic shear strain time history curve

165 Fig.10 shows the relationship between the cumulative plastic strain of the silty sand and subway entrance/exit distances; It can be seen that the cumulative plastic deformation of the silty sand at the same distance from the subway station, whether vertical strain or shear strain, is generally greater in the subway entrance interval than the exit interval. Closer to the subway station, more obvious the cumulated plastic deformation of the soil. For practical engineering, the key prevention and control stage of soil deformation in the area far from the subway station lasts for a long time. The soil near the subway station has large final deformation. Additionally, it should pay more attention to disaster prevention in subway entrance interval. Fig.10 Effects of subway entrance/exit distance on cumulative plastic deformation The reason for the above phenomenon is: closer to the subway station, slower the average subway speed.

174 It takes long time for a slow train to pass through a certain point. This makes the loading of a train closer to 175 the subway station more impulse on the soil under the same condition. The greater strain rate of the soil is conducted by large impulse, which results in a rapid development of soil deformation in the early stage.

177 Nanjing silty sand contains a small amount of clay particles, and the silty sand has a certain viscoplasticity;

178 the impulse can increase the plastic deformation that resulting in the cumulative plastic deformation of the 179 soil near the subway station is large.

\section{0 \\ The effects of subway entrance/exit acceleration on the cumulative plastic deformation}

181 The vertical cumulative plastic strain of the silty sand conducted by 5000 times variable frequency

182 cyclic loading under different subway entrance/exit acceleration is shown in Fig.11. It can be seen that the 183 vertical cumulative plastic deformation conducted by high acceleration is greater. The smaller acceleration, 
the more obvious degree of its influence on the change of deformation. The cumulative plastic shear strain of the silty sand conducted by 5000 times variable frequency cyclic loading under different subway entrance/exit acceleration is shown in Fig.12. It is easy to know that greater the subway entrance/exit acceleration, greater the shear deformation of the soil. Since the "deceleration value" of subways entrance is greater than the "acceleration value" of subways exit, this also indicates that the vertical deformation of the subway entrance interval is greater than subway exit interval, and the shear deformation of the subway entrance interval is less than subway exit interval.

Fig.11 Effects of the acceleration on cumulative vertical plastic deformation

Fig.12 Effects of the acceleration on cumulative plastic shear deformation

The reason for the above phenomenon is: greater the acceleration of the subway entrance/exit, faster the subway running at the same location. The high-frequency vibrations generated by the high-speed train makes the vertical deformation of soil greater. For the shear strain of soil, the shear stress produced by subway acceleration or deceleration has a more direct and deeper impact on it; the test results also show that the shear deformation of soil and the subway acceleration roughly reflect a positive correlation.

\section{The effects of vibration amplitude on the cumulative plastic deformation}

The vertical cumulative plastic strain and shear strain of the silty sand under 5000 times variable frequency cyclic loading with different vibration amplitude of subway entrance/exit are shown in Fig.13 and Fig.14. It can be seen that greater the vibration amplitude of subway entrance/exit loading, greater the vertical cumulative plastic deformation of soil, and also greater the cumulative plastic shear deformation. The greater vibration amplitude is more likely to cause greater plastic deformation of the soil.

Fig.13 Effects of vibration amplitude on cumulative vertical plastic deformation

Fig.14 Effects of vibration amplitude on cumulative plastic shear deformation

\section{The effects of effective confining pressure on the cumulative plastic deformation}

Under different effective confining pressures, the vertical cumulative plastic strain and shear strain of the silty sand conducted by 5000 times variable frequency cyclic loading of subway entrance/exit are shown in Fig.15 and Fig.16. The results show that greater the effective confining pressure of the soil, smaller the vertical cumulative plastic deformation and shear deformation. The soil with greater effective confining pressure has strong resistance to deformation. 
212 Fig.15 Effects of effective confining pressure on cumulative vertical plastic deformation

213 Fig.16 Effects of effective confining pressure on cumulative plastic shear deformation

\section{Cumulative plastic deformation model}

215 The hyperbolic exponential model (Xu 2011) is a prediction model for the long-term deformation of the 216 soil under cyclic loading in the Yangtze River Delta. The relationship between cumulative plastic strain and 217 the number of cyclic vibrations is: parameters that characterize cumulative deformation rate, the deformation of the soil after the first cyclic

221 loading, and the final deformation of the soil.

Under subway entrance/exit loading, after replacing general cyclic loading number with vibration cycles of subway entrance/exit loading, the hyperbolic exponential model is used for fitting. The fitting results are

224 shown in Tab.3. It can be seen that the fitting correlation coefficients are all above 0.985 . The fitting result is pretty well. That is, the hyperbolic exponential model can effectively simulate the development of cumulative plastic deformation of the silty sand under variable frequency cyclic loading of subway entrance/exit.

Tab.3 Prediction model fitting results

\section{Conclusion} and the undrained dynamic cyclic triaxial test. Conclusions are drawn as follows:

(1) The stress state of the soil under the subway entrance/exit loading which includes the compressive stress in the vertical direction and shear stress in the horizontal direction can be equivalent simulated by controlling the principal stress of the samples under a inclined reconstituted angle.

(2) The cumulative plastic strain curve of the silty sand under variable frequency cyclic loading of subway entrance/exit can be roughly divided into three stages: explosive growth, rapid growth, gradual 
stability. The strain of soil in subway entrance/exit interval has the largest growth rate in the initial stage of subway line in operation. It must be the main focus of engineering geological disaster prevention.

(3) The closer to the subway station, fewer vibration cycles of subway entrance/exit loading the soil needs to enter the gradual stabilization phase, the greater vertical settlement, and the smaller shear deformation will occur. The soil rapid growth phase in the area far from the subway station lasts for a long time, and the soil near the subway station will quickly settle down.

(4) Greater the acceleration (deceleration) of subway entrance/exit, smaller the vertical deformation of soil, and greater the shear deformation. The settlement deformation of the soil in subway entrance interval and the horizontal displacement of the soil in subway exit interval are much severer.

(5) Greater the vibration amplitude of the subway loading, Greater the cumulative plastic deformation of the silty sand; Greater the effective stress of the silty sand, stronger its ability to resist loading deformation.

\section{Acknowledgements}

The research work herein was supported by National Natural Science Foundation of China (No. 41702299) and Foundation of State Key Laboratory of Frozen Soil Engineering (No. SKLFSE201916)

\section{Reference}

Chen WH, Sun M, Liu ML, et al. (2003) Characters of Schistose Structure of Nanjing's Sand and Seismic Liquefaction of Subsoil of a Metro Section. Rock and Soil Mechanics, 24 (5), 755-758.

Chen WH, Zhang Q (2019) Space vibration of subsoil during metro train arriving at or leaving station. Rock and Soil Mechanics, 40(09), 3656-3661+3669.

Degrande G, Schevenels, M, Chatterjee P, et al. (2006). Vibrations due to a test train at variable speeds in a deep bored tunnel embedded in London clay. Journal of Sound and Vibration, 293(3-5), 626-644.

He W (2018). Vertical dynamics of a single-span beam subjected to moving mass-suspended payload system with variable speeds. Journal of Sound and Vibration, 418, 36-54.

Hu ZH, Wang R, Zhuang HY, et al. (2016) Apparent Kinetic Viscosity of Saturated Nanjing Sand Due to LiquefactionInduced Large Deformation in Torsional Shear Tests [J]. Chinese Journal of Geotechnical Engineering, 38 (S2), 149-154. in Chinese

Huang MH, Thambiratnam DP (2001) Deflection response of plate on Winkler foundation to moving accelerated loads. Engineering Structures, 23(9), 1134-1141. 
Karimi AH, Ziaei-Rad S (2015) Vibration analysis of a beam with moving support subjected to a moving mass travelling with constant and variable speed. Communications in Nonlinear Science \& Numerical Simulation, 29(1-3), 372390.

Kim SM, Mccullough BF (2003) Dynamic response of plate on viscous winkler foundation to moving loads of varying amplitude. Engineering Structures, 25(9), 1179-1188.

Lu Z, Yao HL, Wu S, et al. (2010) Vibration analysis of a plate on viscoelastic foundation under moving rectangular loads with variable speeds. Rock and Soil Mechanics, 31(11), 3613-3618.

Michaltsos GT (2002) Dynamic behavior of a single-span beam subjected to loads moving with variable speeds. Journal of Sound \& Vibration, 258(2), 359-372.

Ren X, Tang Y, Xu Y, et al. (2011) Study on dynamic response of saturated soft clay under the subway vibration loading I: instantaneous dynamic response. Environmental Earth Sciences, 64(7), 1875-1883.

Tang Y, Li J (2018) Test method and application for microstructures of undisturbed silty sand and sandy silt. Environmental Earth Sciences, 77(18).

Tang YQ, Cui ZD, Zhang X, et al. (2008) Dynamic response and pore pressure model of the saturated soft clay around the tunnel under vibration loading of shanghai subway. Engineering Geology, 98(3-4), 126-132.

$\mathrm{Xu} \mathrm{J}$ (2011) Study on the nonlinear natural frequency and macro-micro environmental vibration response of the formation system under the load of rail transit (Doctoral dissertation, Tongji University).

Zhang Q, Chen WH (2016) Out-of-plane vibration induced by axial excitation while metro train arriving at or leaving station. Journal of Vibration and Shock, 2016, 35(24), 102-108.

Zhang Q, Chen WH (2017) Cylindrical longitudinal vibration while metro train arriving at station. Journal of Vibration Engineering, 30(3), 442-448.

Zhang N, Xia H, Cheng Q, et al. (2011) Analysis method for a vehicle structure coupled system under braking force. Vibration and Shock, 30(02), 138-143.

Zhou J, Tang Y (2018) Practical model of deformation prediction in soft clay after artificial ground freezing under subway low-level cyclic loading. Tunneling and Underground Space Technology, 76(JUN.), 30-42. 
Figures

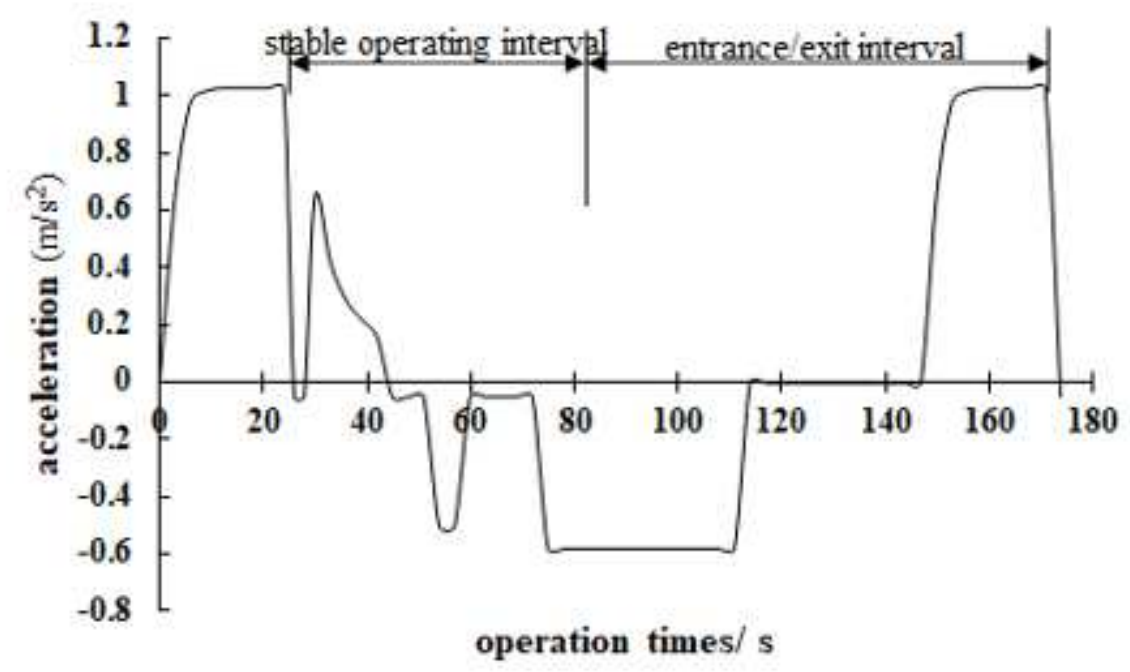

(a)

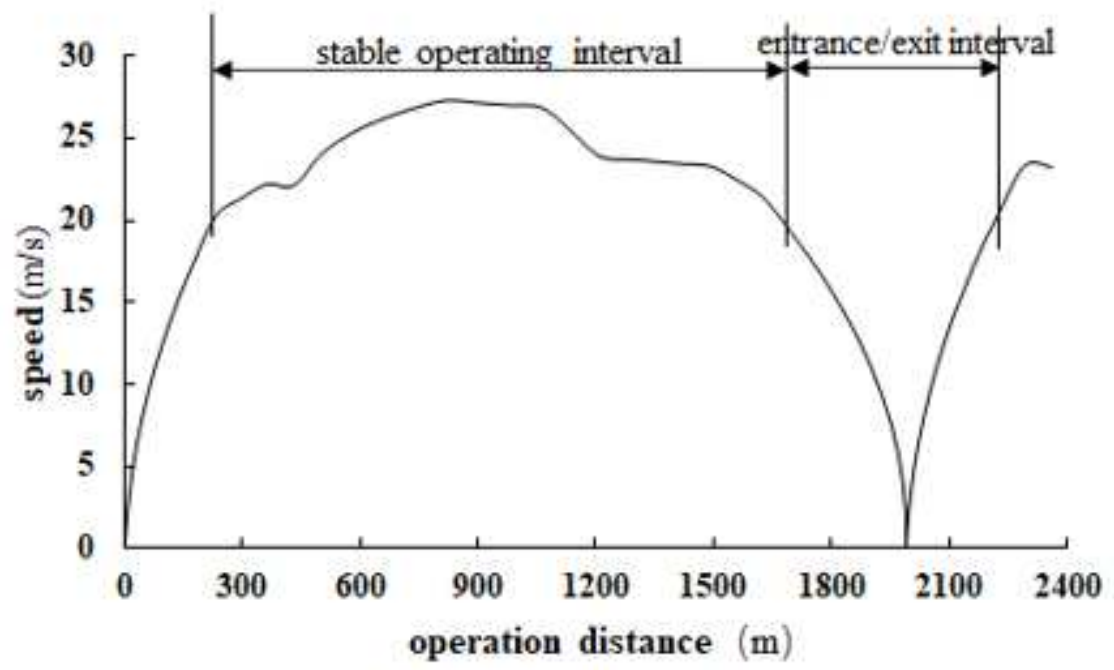

(b)

\section{Figure 1}

Speed curve of Nanjing Metro in operation (a) time; (b) distance 


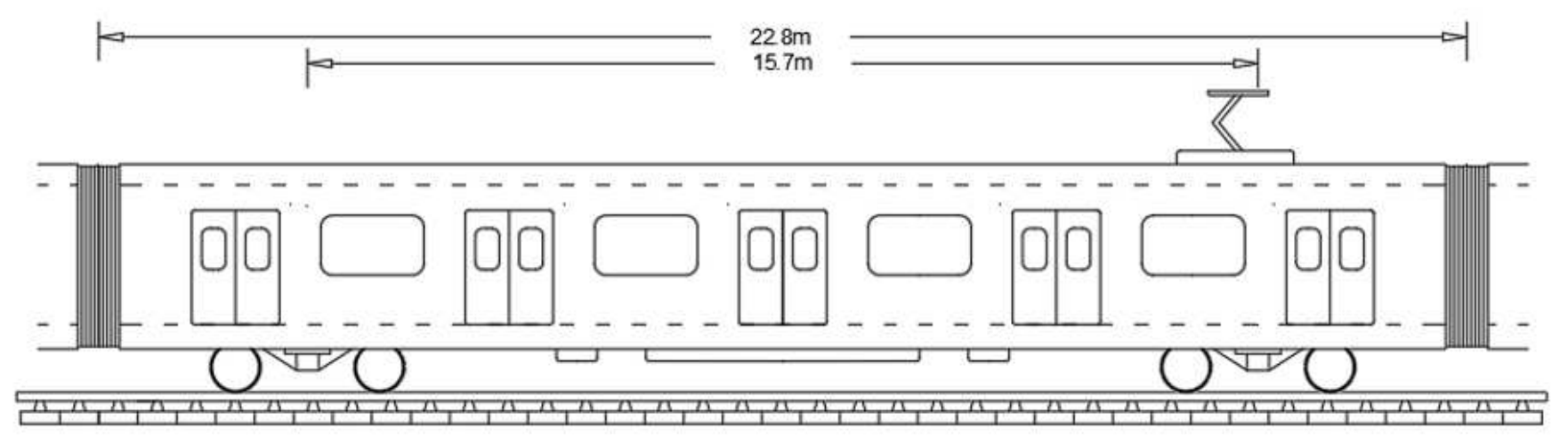

Figure 2

The subway carriages size of Nanjing Metro

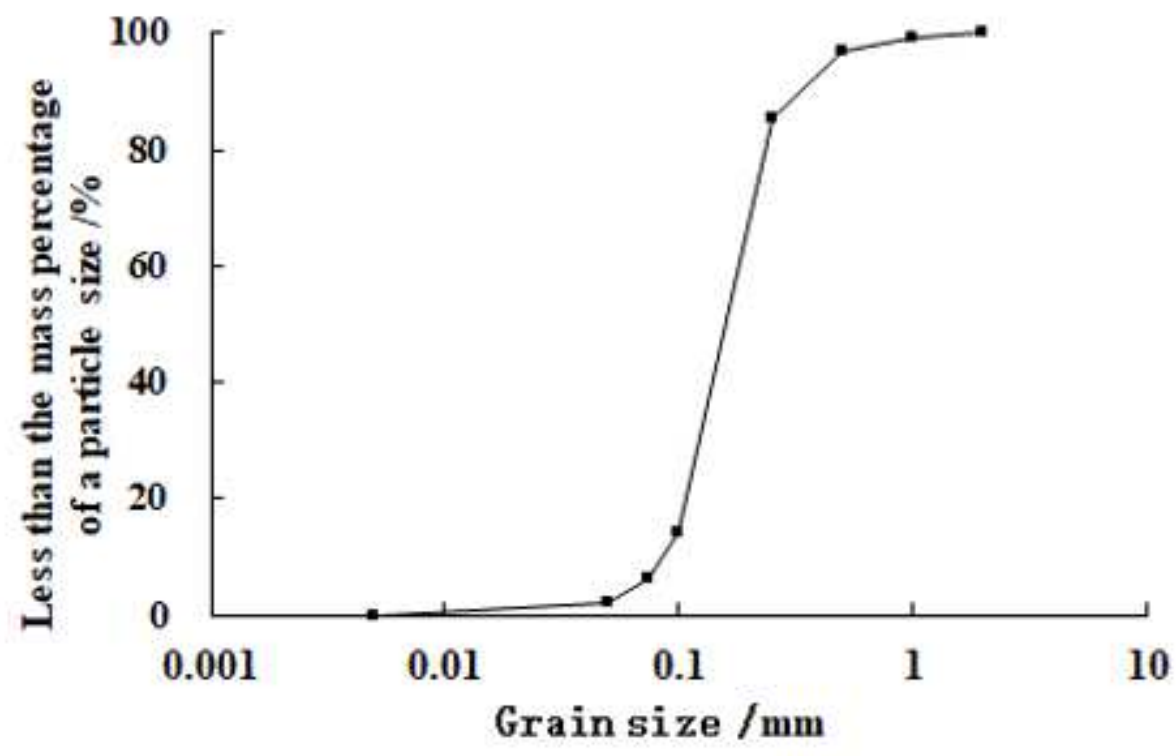

(a)

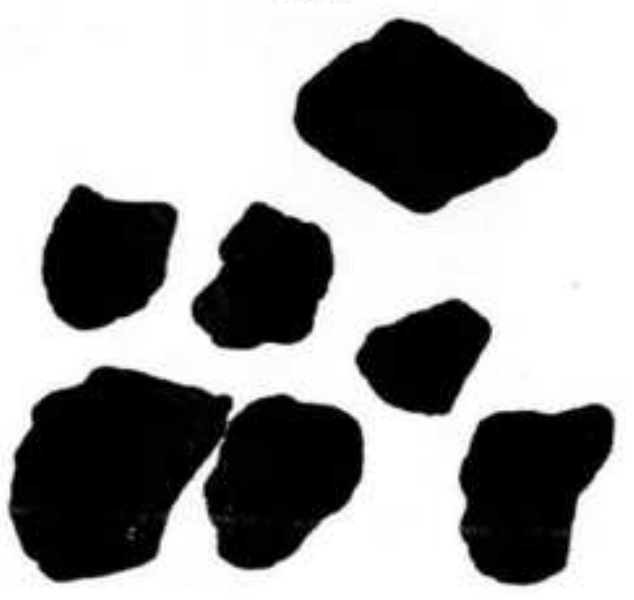

(b) 
Figure 3

Particle characteristics of Nanjing silty sand (a)grain size; (b)particle shape
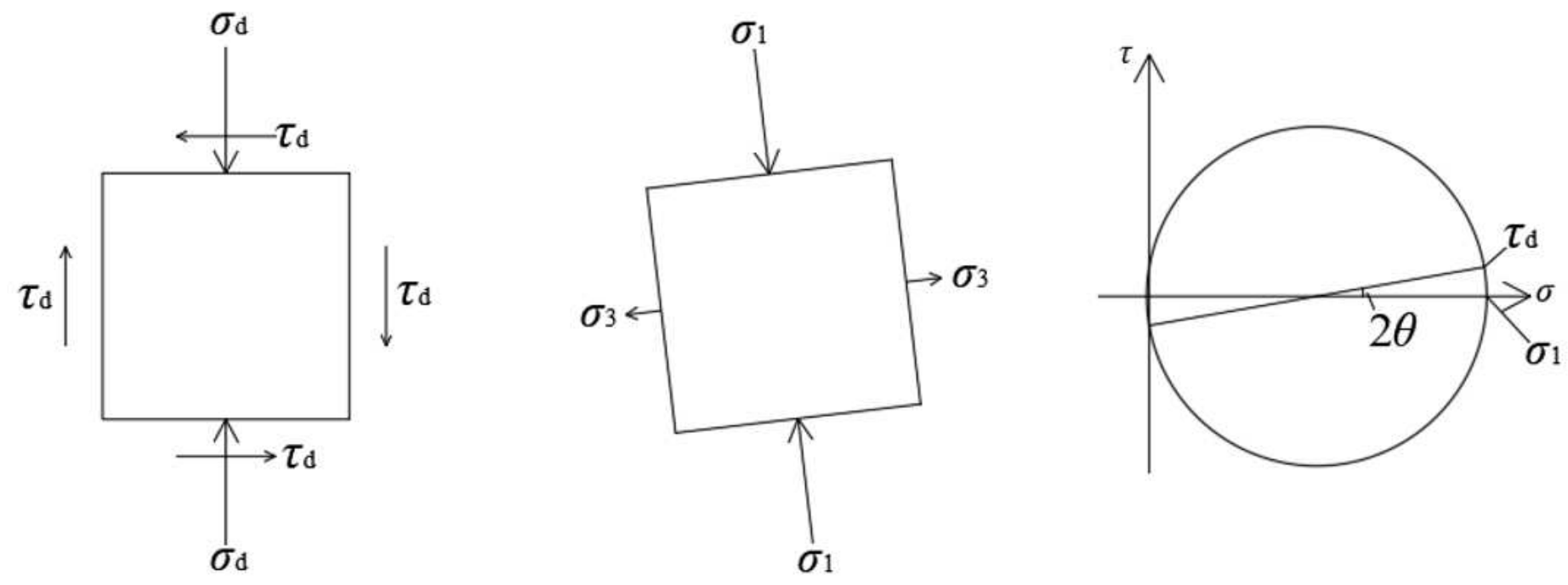

Figure 4

Soil stress state under the loading of subway entrance/exit

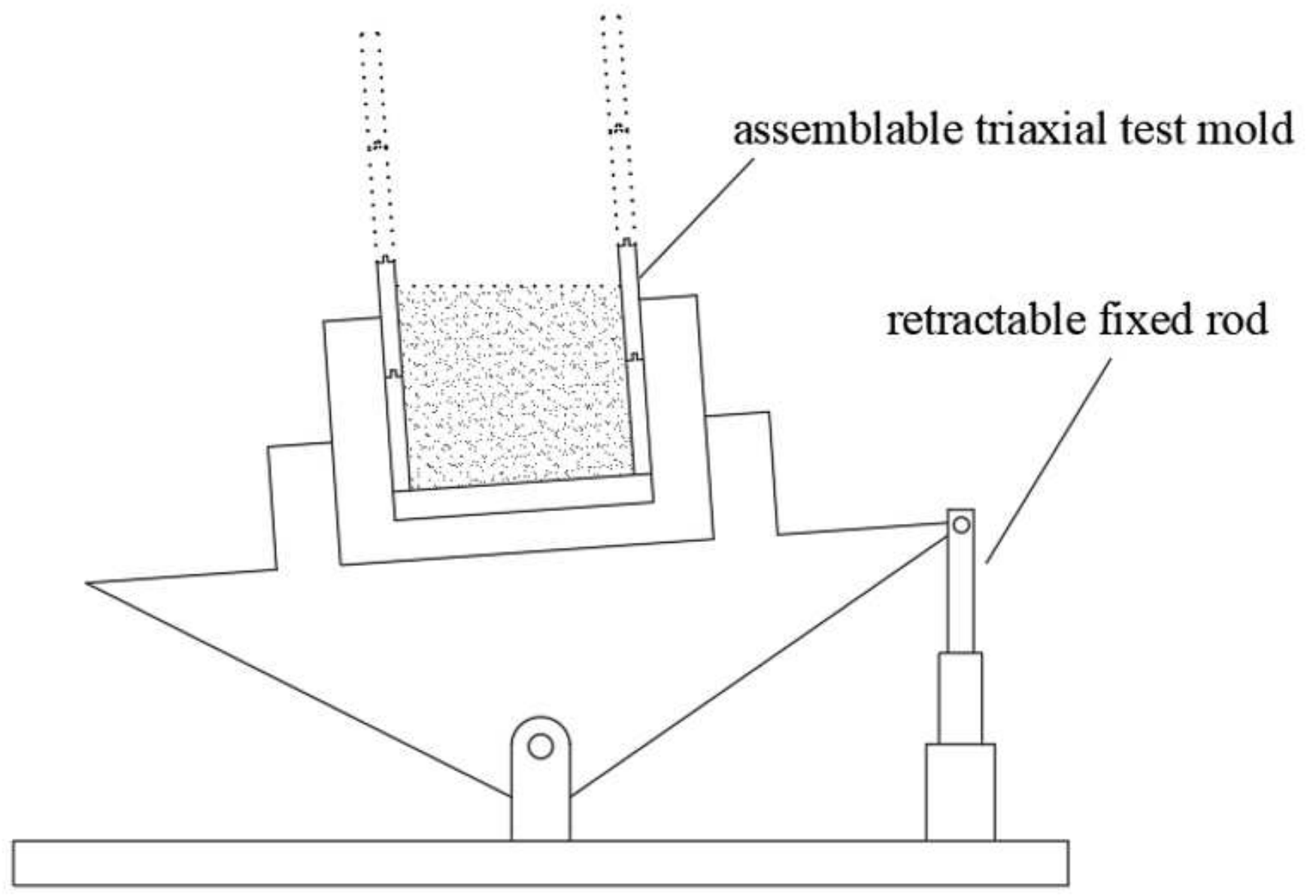


Figure 5

Sample preparation device of underwater rain method

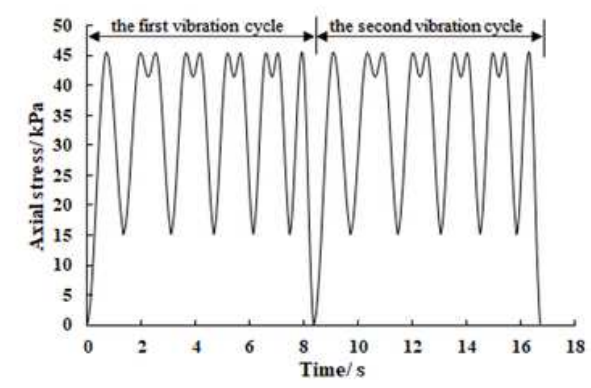

(a)

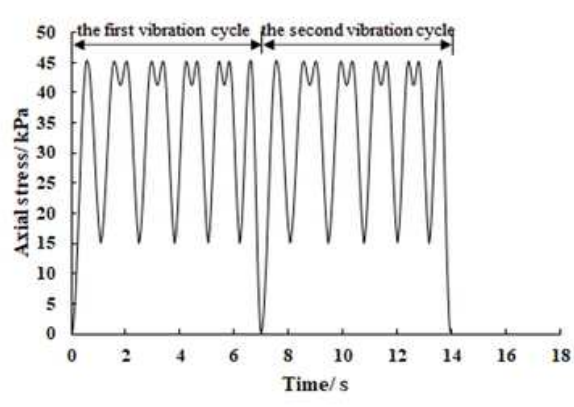

(b)

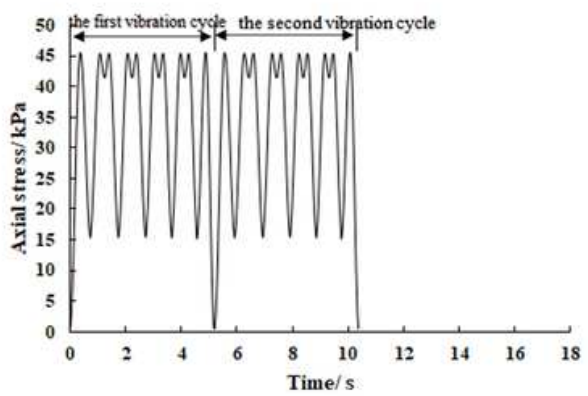

(c)

Figure 6

Dynamic triaxial axial compression stress time history curve (a) B4; (b)B5; (c)B6

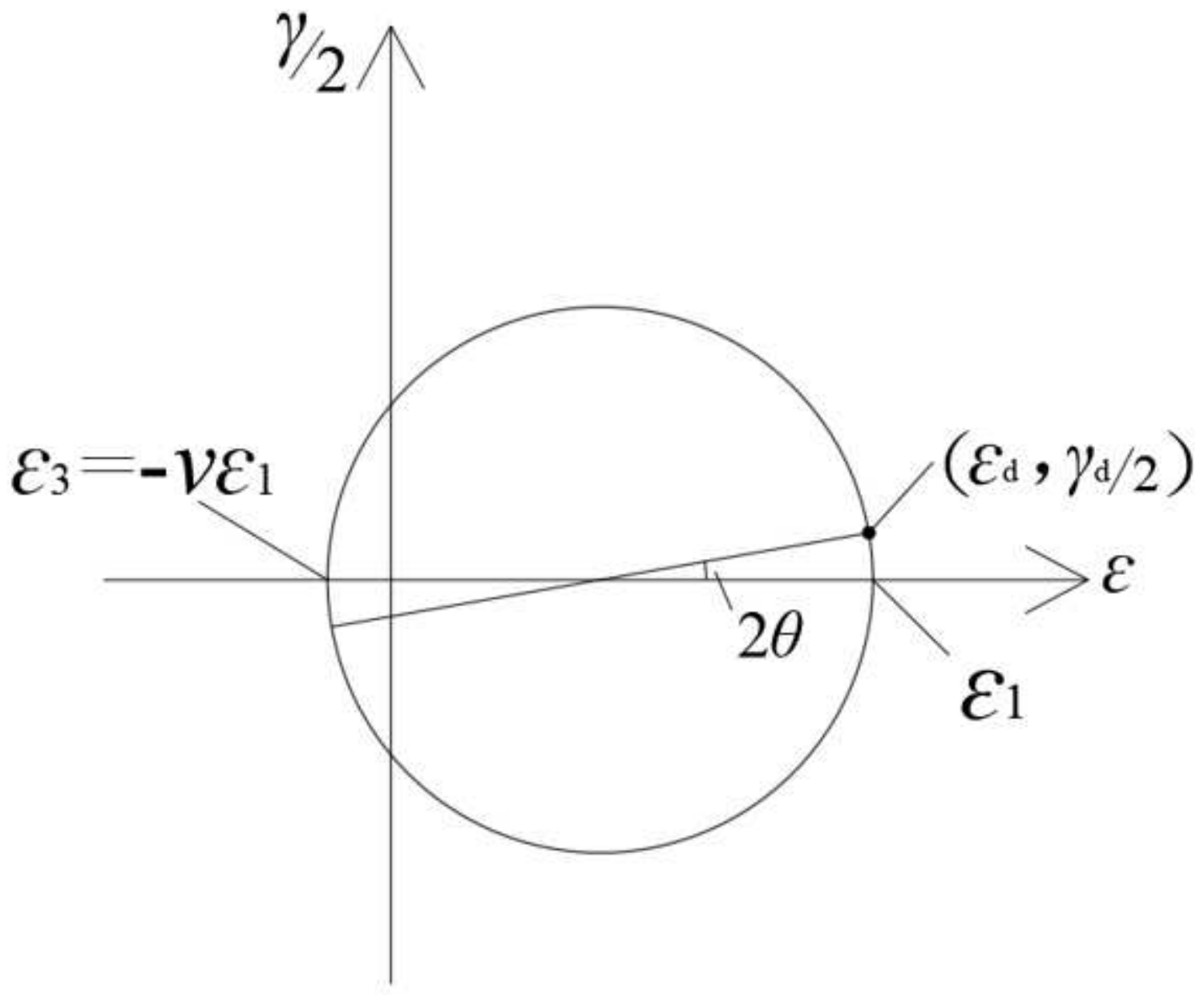

Figure 7

Soil strain state under the loading of subway entrance/exit 


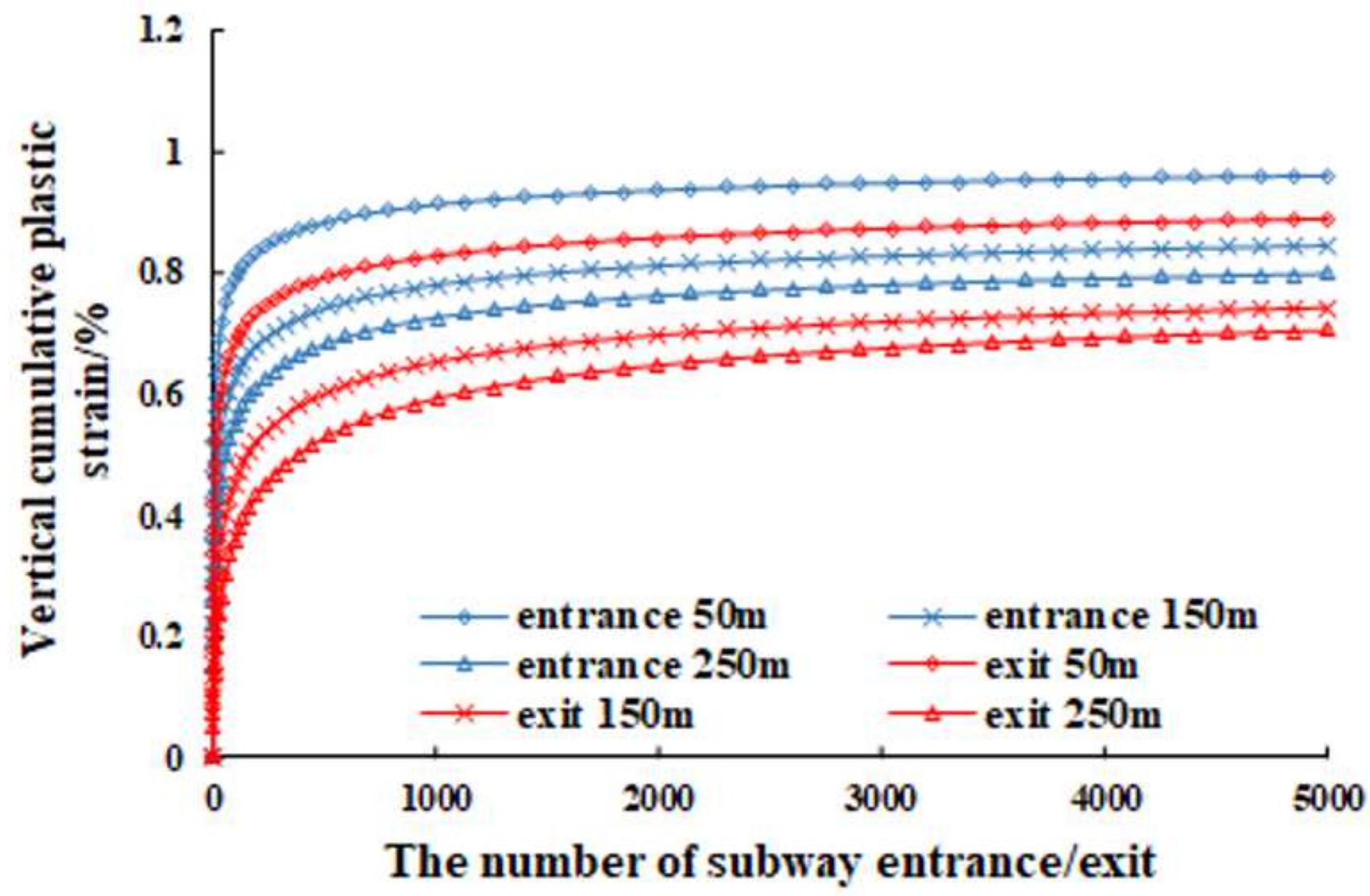

Figure 8

Cumulative vertical plastic strain time history curve 


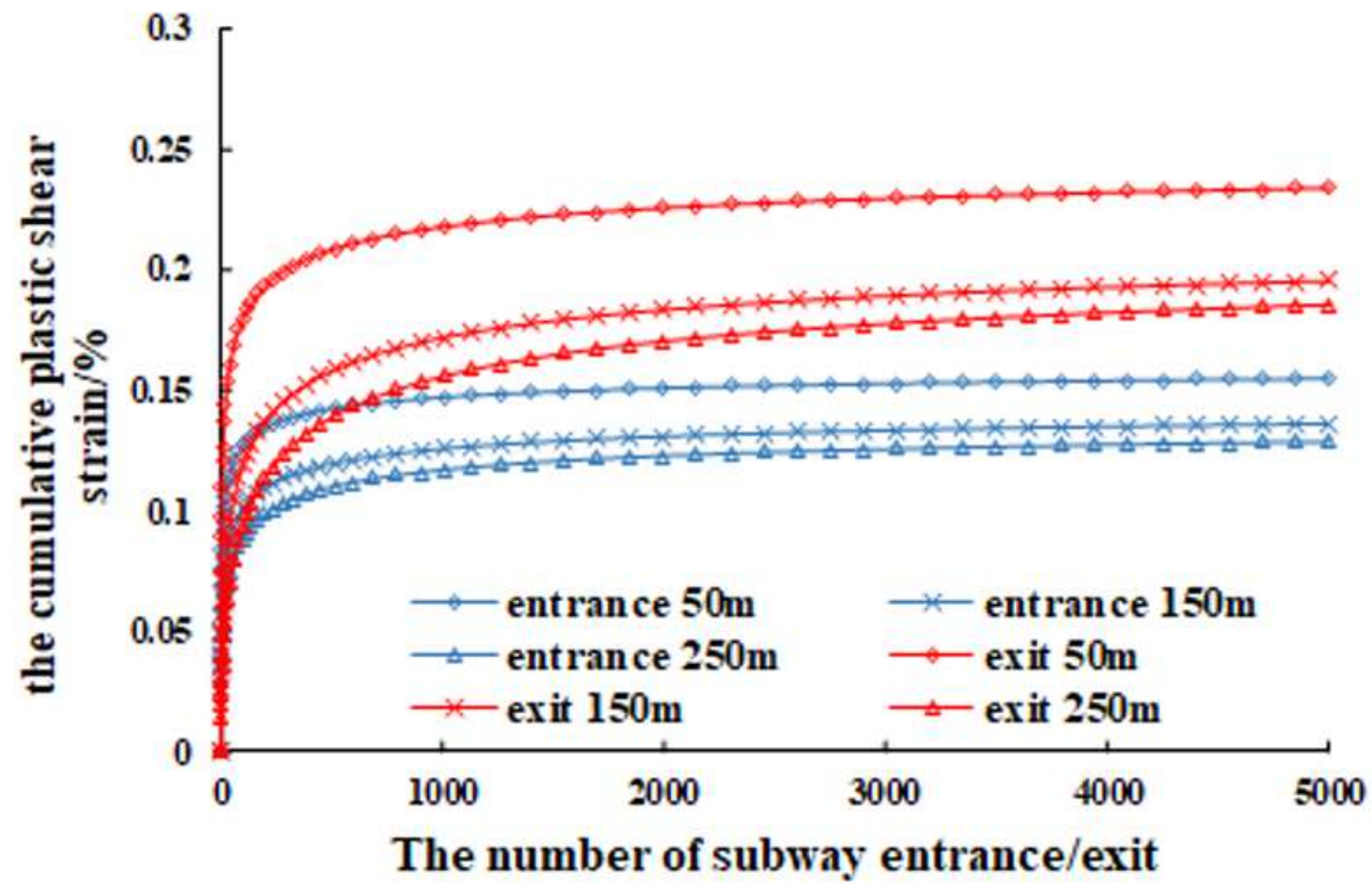

Figure 9

Cumulative plastic shear strain time history curve 


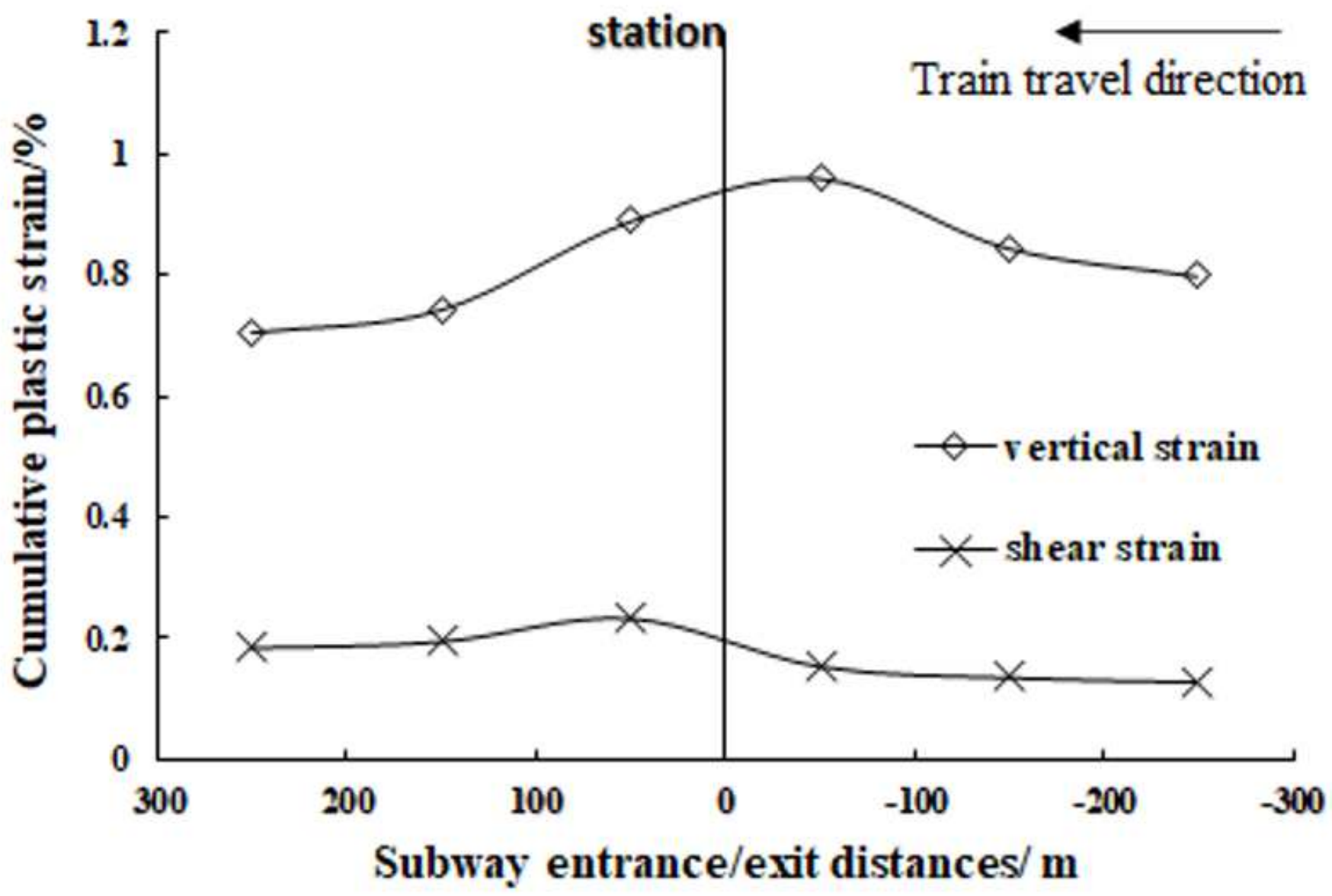

Figure 10

Effects of subway entrance/ exit distance on cumulative plastic deformation 


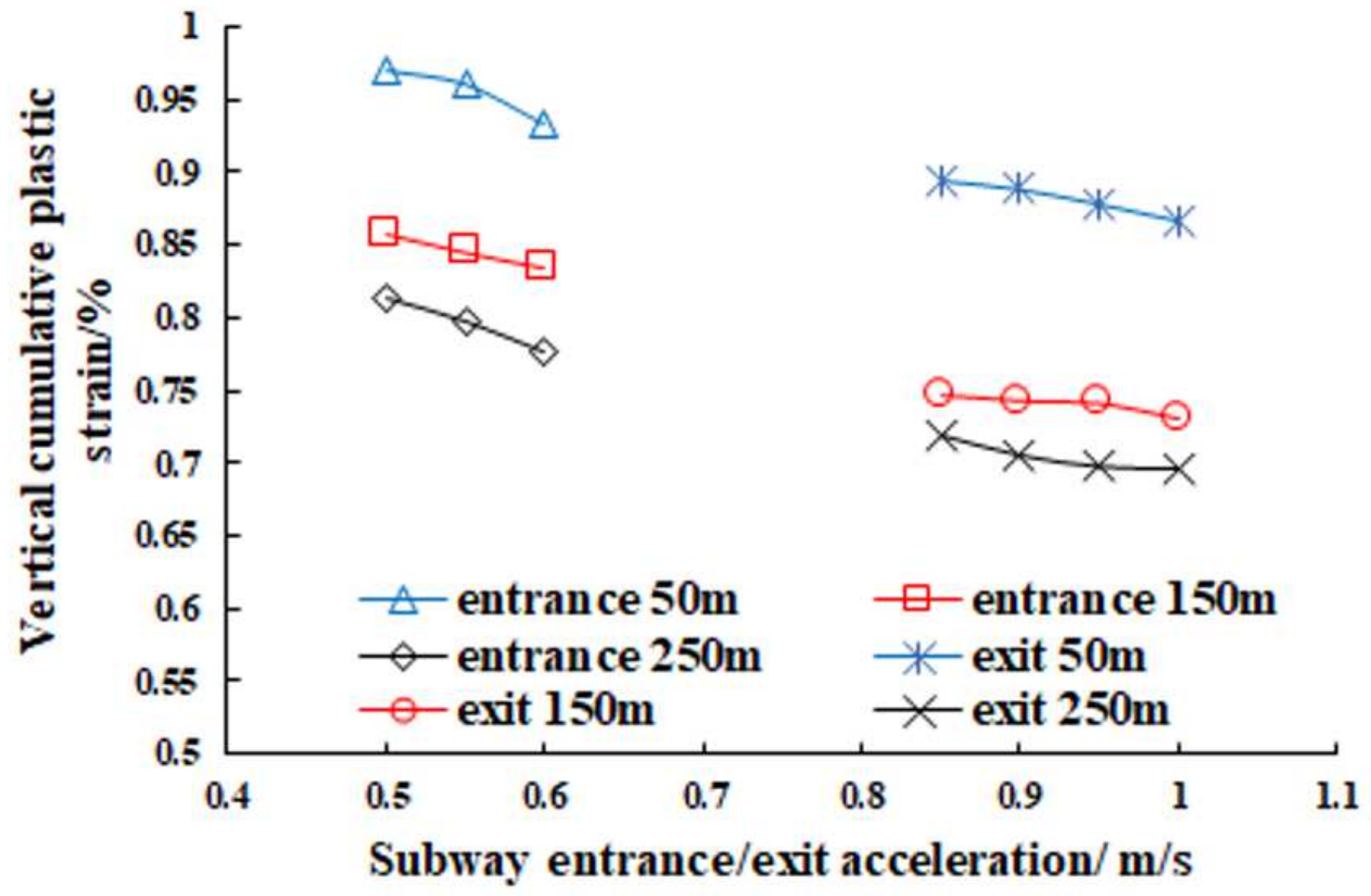

Figure 11

Effects of the acceleration on cumulative vertical plastic deformation 


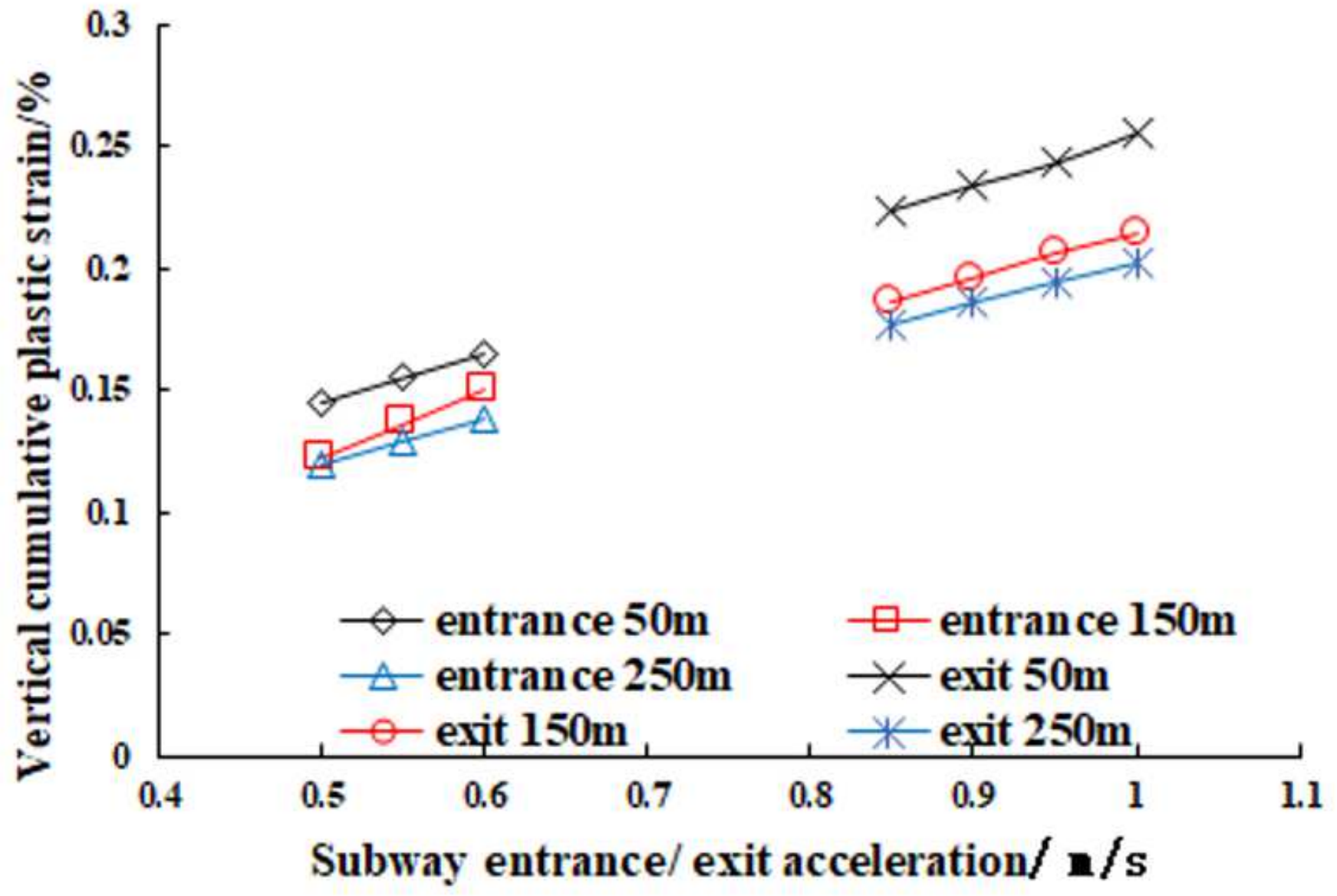

Figure 12

Effects of the acceleration on cumulative plastic shear deformation 


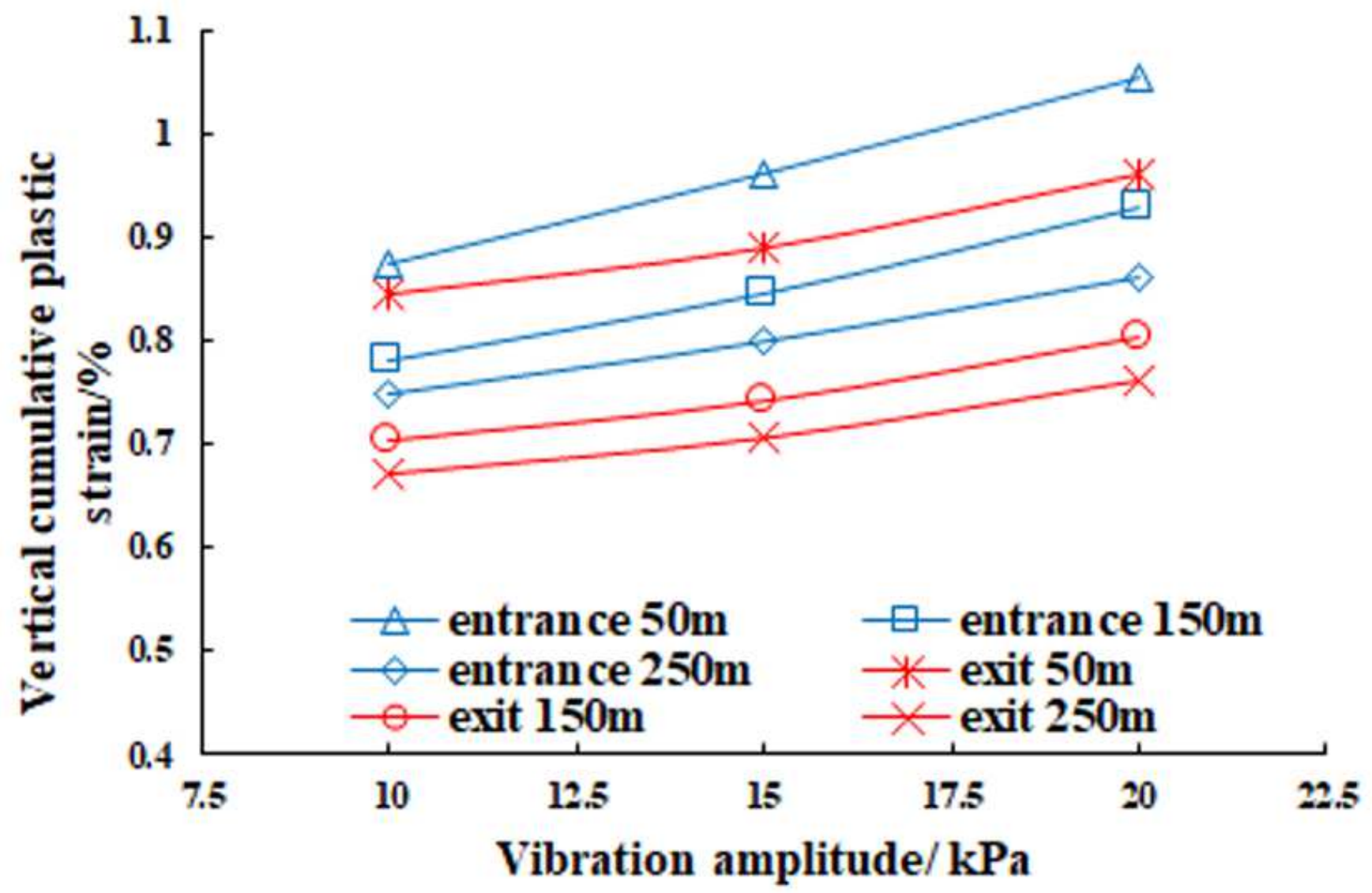

Figure 13

Effects of vibration amplitude on cumulative vertical plastic deformation 


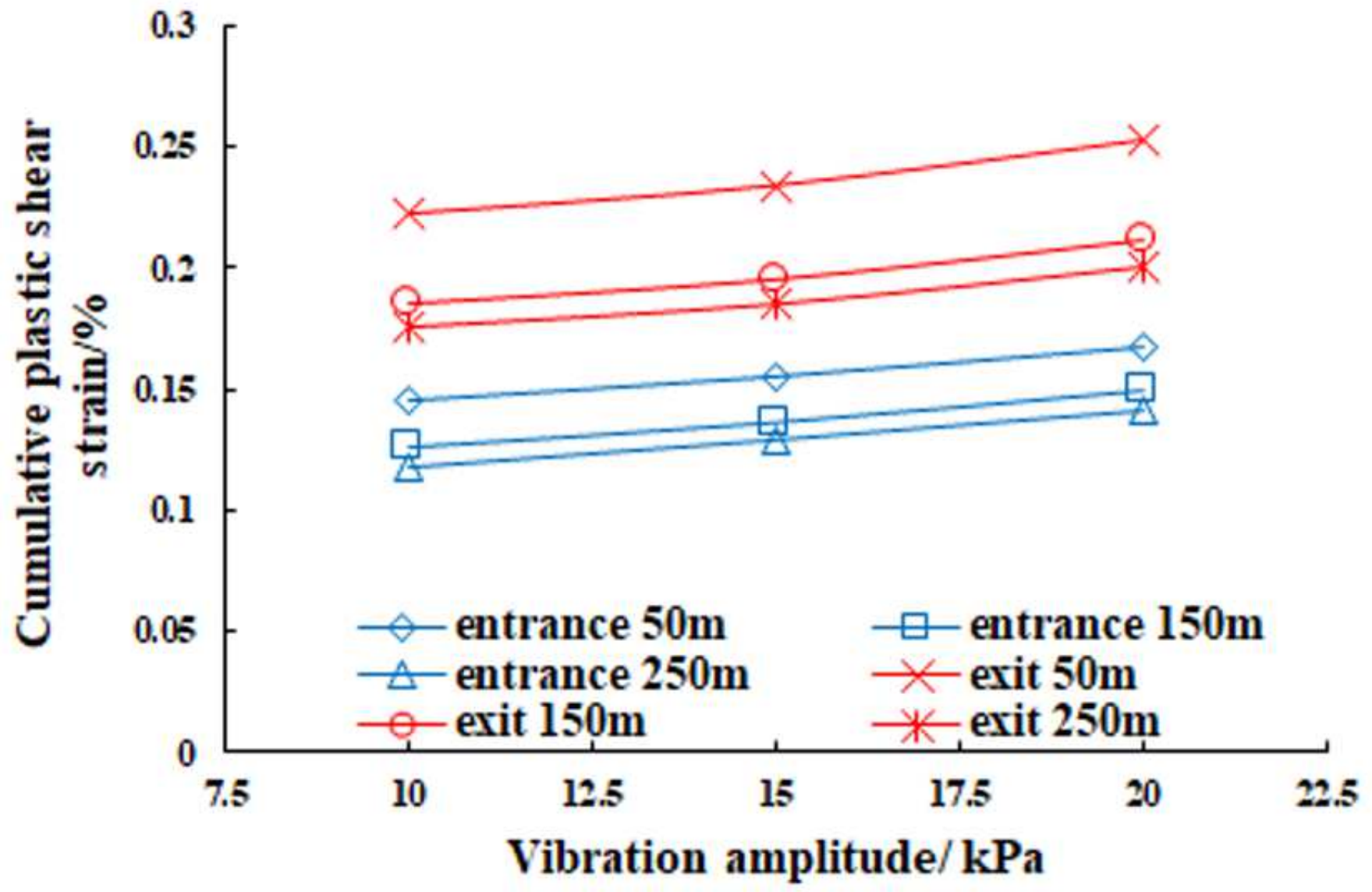

Figure 14

Effects of vibration amplitude on cumulative plastic shear deformation 


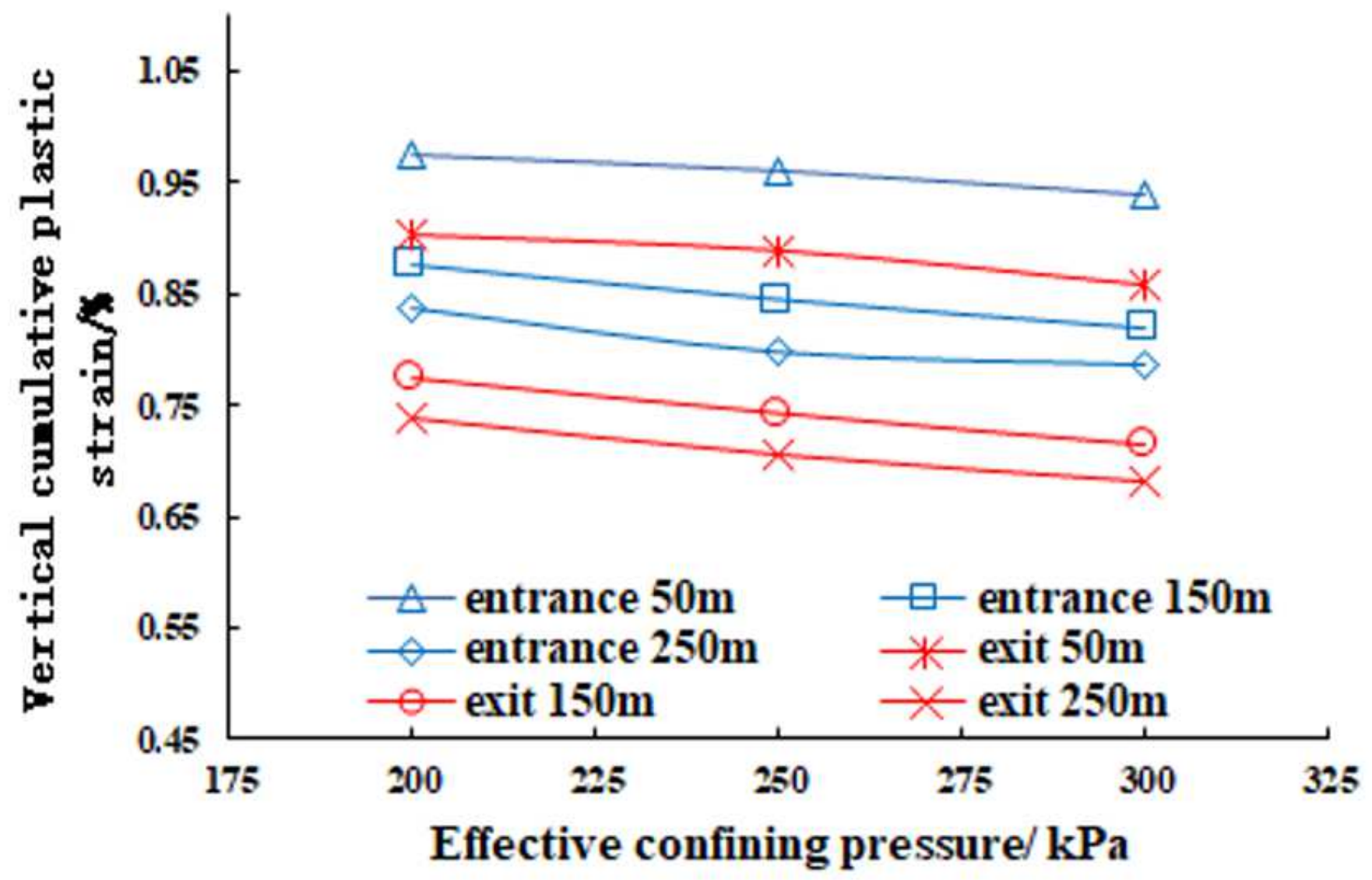

Figure 15

Effects of effective confining pressure on cumulative vertical plastic deformation 


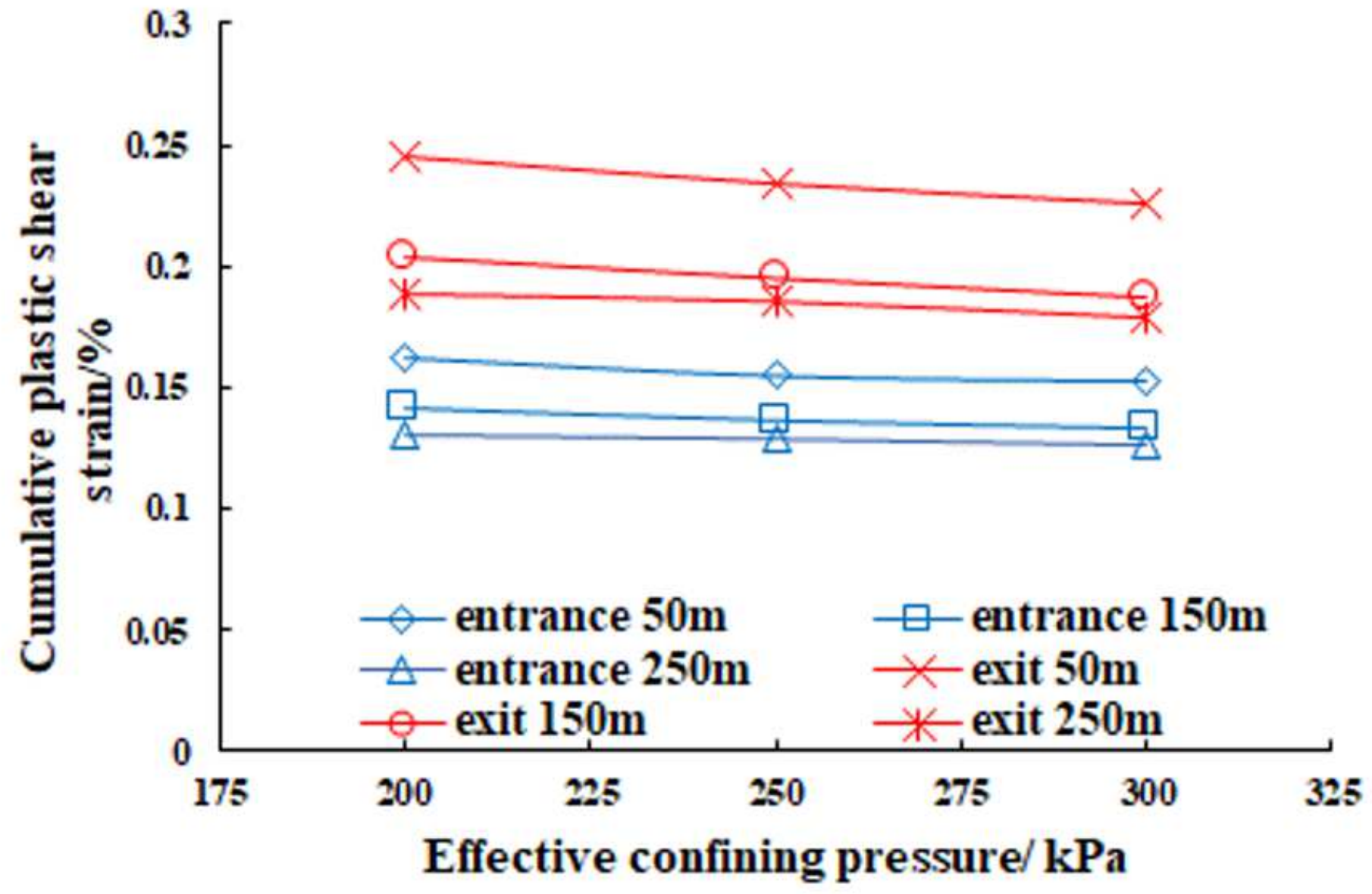

Figure 16

Effects of effective confining pressure on cumulative plastic shear deformation

\section{Supplementary Files}

This is a list of supplementary files associated with this preprint. Click to download.

- Tables.docx 